\title{
O MURO COMO LIMITE: METAFORIZANDO O ESPAÇO DAS MINORIAS SOCIAIS EM MURALHAS DA INFÂNCIA E UM ANIMAL MENOR
}

\author{
Laísa Veroneze Bisol ${ }^{1}$
}

Resumo: Esta pesquisa objetiva compreender o modo como as minorias sociais são representadas em duas produções artísticas de narrativas curtas mas de ordem discursiva distinta: a literatura, através do miniconto "Muralhas da Infância", de Ana Mello, e cinema, a partir do curta-metragem "Um animal menor", de Pedro Harres e Marcos Contreras. Para discorrer sobre o tema, abarcaremos as ideias acerca da representação, através de autores como Luiz Costa Lima (2006), Erich Auerbach (1971)e Rejane Pivetta de Oliveira (2003), além de comentarmos a respeito das minorias sob a perspectiva da estudiosa Regina Dalcastagnè $(2005,2008)$. As personagens minoritárias que analisamos são uma criança e uma mulher, respectivamente. Através da leitura crítica das narrativas, concluímos que o "muro", que aparece como um limite em ambas as narrativas, pode inferir a uma metáfora para os diversos impeditivos sociais dos grupos minoritários.

Palavras-chave: Literatura. Cinema. Representação. Minorias.

\begin{abstract}
This research objective to understand how social minorities are represented in two artistic productions of short narratives but of a different discursive order: literature, through the tale mine "Muralhas da Infância" by Ana Mello, and cinema, from the short film "Um animal menor", by Pedro Harres and Marcos Contreras. To discuss the topic, we will cover the ideas about representation, through authors like Luiz Costa Lima (2006), Erich Auerbach (1971) and Rejane Pivetta de Oliveira (2003), as well as commenting on minorities from the perspective of the scholar Regina Dalcastagnè $(2005,2008)$. The minority characters that we analyzed are a child and a woman, respectively. Through the critical reading of the narratives, we conclude that the "wall", which appears as a limit in both narratives, can infer a metaphor for the various social impediments of minority groups.
\end{abstract}

Keywords: Literature. Movie. Representation. Minorities.

\footnotetext{
${ }^{1}$ Doutoranda em Letras - Estudos Literários na Universidade Federal de Santa Maria (UFSM). Mestre em Letras - Literatura Comparada pela Universidade Regional Integrada (URI). Jornalista graduada pela UFSM. Professora substituta do Departamento de Comunicação da UFSM - FW. E-mail: laisabisol1@gmail.com.
} 
As narrativas, sejam elas de origem literária, cinematográfica, jornalística, ou outras, atuam como uma possibilidade de resgatar acontecimentos através de sua representação, trazendo presente aquilo que já aconteceu e fazendo conhecer determinados fatos.

Tendo isso em vista, podemos pensar o papel da representação no campo das artes. Representar, através de objetos artísticos, não consiste em remontar a realidade, mas, por outro lado, os mais diferentes discursos são capazes de trazer à tona versões de realidades, que podem ser decodificadas pelo público receptor.

Luiz Costa Lima (2006) aponta que a ficção não está apenas na literatura, mas no cotidiano das pessoas; contudo, objetos ficcionais não fazem parte do objetivo da narrativa histórica. Partindo desse pressuposto, podemos considerar a ideia de que, entre as funções da narrativa histórica enquanto não-ficcional, estaria a de narrar episódios, sem a necessidade de incrementá-los com outros elementos do campo ficcional. Ao considerar a cultura grega em torno da mimesis, abordada nas teorias platônica e aristotélica, Luiz Costa Lima (2003, p. 79) conclui que é na arte que a mimesis se concretiza, tendo como base a experimentação com o outro para "saber-se, nesta alteridade, a si mesmo". Sendo assim, as relações entre aquele que escreve e o objeto de sua narrativa são fundamentais para a construção desta realidade representada através da ficção.

Consideramos, ainda, a perspectiva de Rejane Pivetta de Oliveira (2003), a autora afirma que a mimesistraria consigo uma essência humana, sendo uma forma de representar anseios e empecilhos para os quais os indivíduos buscam respostas. Dessa forma, a imitação não seria reduzida ao imediatismo dos fatos, uma vez que o processo de captar a realidade perpassa por uma seleção em que o narrador define aquilo que é mais relevante sobre as situações antes de transpassá-las para o discurso artístico. Citando Lukács, Oliveira (2003) traz a ideia de que através da mimesis é possível que se crie uma consciência do universo, já que a imitação não seria simplesmente uma cópia da realidade, mas, sim, uma representação transformadora e geradora de conhecimento.

As artes ficcionais, por carregarem a possibilidade do imaginário, daquilo que está além do histórico, são capazes de produzir significados que não se constroem somente pela percepção dos fatos, mas sim pela probabilidade de reflexão. Isso quer dizer, ao passo em que se desenvolve um discurso, recriando 
momentos, apresentando diferentes situações, há também uma grande probabilidade de comparação entre o real, proporcionado pelo discurso histórico, e o fictício das artes, promovendo uma nova noção e entendimento de situações que permeiam o cotidiano e a memória social. Ponderando o papel do narrador nesta construção, Auerbach comenta:

Assim, por exemplo, aqui, onde o escritor atinge a impressão mencionada colocando-se a si próprio, por vêzes, como quem duvida, interroga e procura, como se a verdade acêrca da sua personagem não lhe fôsse mais bem conhecida do que às próprias personagens ou ao leitor. Tudo é, portanto, uma questão da posição do escritor diante da realidade do mundo que representa; posição que é, precisamente, totalmente diferente da posição daqueles autores que interpretam as ações, as situações e os caracteres das suas personagens com segurança objetiva [...] (AUERBACH, 1971, p.470).

Tomando este pensamento como pressuposto, compreendemos que todo o ato de representação, inicia com um anseio e perpassa por um narrador que reconhece esta necessidade, entende os fatos e escreve sobre esta realidade, dando a conhecer, ou, salvaguardar o mundo e suas situações.

A partir destas considerações, reafirmamos a ideia de que a representação, seja através da literatura ou do cinema, é capaz de atribuir um novo sentido aos fatos narrados, possibilitando um novo entendimento em torno daquilo que aconteceu e posteriormente é reconstruído. Sendo assim, notamos a importância do enunciador no ato de selecionar as informações e o modo como irá transmiti-las.

Ao aliar as discussões sobre representação com a questão das minorias, nos deparamos com algumas reflexões diante daquilo que é mostrado através das narrativas de ordem artística ou, por outro lado, silenciado através das artes. Compreendemos que estas manifestações podem estar munidas de elementos que não visam apenas o entretenimento dos públicos mas, sobretudo, a representação de aspectos sociais que podem causar, ao receptor, sensações, sentimentos, e, em especial, a oportunidade de refletir sobre o que é exposto.

Antonio Candido (1995), afirma que a função da literatura está ligada à complexidade da sua natureza, que tem um fim humanizador. O crítico ainda expande suas preposições comentando a respeito de outras artes: 
A arte é social em dois sentidos: depende da ação de fatores do meio, que se exprimem na obra em graus diversos de sublimação; e produz sobre os indivíduos um efeito prático, modificando a sua conduta e concepção do mundo, ou reforçando neles o sentimento dos valores sociais. Isto decorre da própria natureza da obra e independe do grau de consciência que possam ter a respeito os artistas e os receptores de arte (CANDIDO, 2000, p. 19).

Entendendo a arte como uma forma de comunicação expressiva e expressão da realidade, verifica-se que através da obra, sua estrutura e função diante do público, o leitor obtém, segundo Candido, mais que uma transmissão de noções e conceitos, pois estabelece uma relação fecunda entre a obra, o público e o leitor. Esta tríade, conforme Candido suscita a relação do artista e suas questões individuais, a sua relação com determinado grupo social e o que estes grupos refletem na sociedade, que influencia na obra, na forma, e através dela, nas suas possibilidades de atuação no meio. Nas palavras do autor:

\begin{abstract}
Entendo por humanização o processo que confirma no homem aqueles traços que reputamos essenciais, como exercício da reflexão, a aquisição do saber, a boa disposição para com o próximo, o afinamento das emoções, a capacidade de penetrar nos problemas da vida, o senso da beleza, a percepção da complexidade do mundo e dos seres, o cultivo do humor (CANDIDO 1995, p. 249).
\end{abstract}

A partir destas ponderações, podemos compreender que, ao representar os grupos minoritários, as artes, através de seus narradores, podem auxiliar neste processo de humanização, contribuindo para novas percepções a respeito das realidades sociais.

A pesquisadora Regina Dalcastagnè (2008) afirma que há, na literatura brasileira, uma histórica ausência de representantes das classes populares, o que ocorre também em outros espaços como na mídia, na academia, ou no governo. Por outro lado, conforme a autora, os estudiosos estão preocupados em debater estas questões de representatividade com relação aos diferentes grupos sociais, por vezes excluídos. As minorias referem-se, por exemplo, a "todos aqueles que vivenciam uma identidade coletiva que recebe valoração negativa da cultura dominante, sejam definidos por sexo, etnia, cor, orientação sexual, posição nas 
relações de produção, condição física ou outro critério" (DALCASTAGNÉ, 2008, p.78).

A autora ainda realizou um outro estudo no que diz respeito a esta representatividade, quando, em 2005, analisou a personagem do romance brasileiro a fim de observar, entre outros fatores, qual o perfil dominante e, assim, quais grupos aparecem nesta produção em detrimento de outros. Dalcastagnè apresentou resultados que geram debates e provocam ainda outras indagações. O perfil dominante da personagem do romance brasileiro contemporâneo é de um ser humano, homem, branco, heterossexual, de idade adulta e mais bem sucedido do que as personagens mulheres. A autora apresenta ainda outro dado relevante: somente $7,9 \%$ das personagens masculinas e $6,4 \%$ das femininas possuem sua infância presente nos textos, isso considerando apenas aquelas narrativas que as personagens são crianças em algum momento do texto.

Estas constatações nos permitem inferir que, também em outras artes, é incomum grupos minoritários serem representados com voz ativa. Mulheres, crianças, negros e homossexuais, por exemplo, não têm a preferência no centro das narrativas.Nesta perspectiva, o pesquisador Lizandro Carlos Calegari (2012) realizou um estudo sobre a representatividade de mulheres, gays e negros, no cânone literário e concluiu que "esses grupos, ao lado de outros, por terem sido colocados à margem da sociedade, da história e da literatura, denunciam sua condição de exclusão, mas principalmente de sofrimento" (CALEGARI, 2012, p. 43). O autor ainda acrescenta que na atualidade os debates acadêmicos e as produções artísticas têm se ocupado mais que outrora dessas questões, embora de maneira ainda tímida.

A fim de compreendermos de que forma as minorias têm sido representadas nas artes, elegemos como objeto de estudo para este trabalho duas narrativas curtas de formatos discursivos diferenciados. O miniconto "Muralhas da Infância", de Ana Mello, fui publicado em 2009faz parte do livro Minicontando, vencedor do prêmio Livro do Ano, categoria narrativa curta, da Associação Gaúcha de Escritores, no ano de 2010. Também analisaremos o curta-metragem "Um animal menor", roteirizado por Pedro Harres e Marcos Contreras, que foi vencedor do Prêmio Assembleia Legislativa de Cinema, inserido no Festival de Cinema de Gramado, também em 2010. 
Optamos por estas produções, tendo em vista que apresentam em seus enredos personagens que fazem parte dos grupos minoritários, são, nestas narrativas: mulher e criança. Além disso, por tratarem-se de produções premiadas em importantes competições, inferimos que são produções de destaque, avaliadas por pareceristas com conhecimentos específicos que, diante de alguns critérios, entenderam as obras como superiores diante de outras que concorreram na mesma competição, ou seja, em função desta condecoração, merecem nossa atenção e estudo.

Com vistas a iniciar a discussão em torno destas produções, apresentaremos cada uma delas, iniciando pelo miniconto "Muralhas da infância" (2010):

$$
\text { O muro é alto. }
$$

Do outro lado outro mundo. Com pitanga, laranja madura, goiaba.

E a bola de futebol.

A gurizada incentiva: vai, não desiste.

Acelero no cinamomo e freio no cachorro do general.

A narrativa, ainda que se apresente de forma sucinta, permite diversas reflexões. Primeiramente verificamos a personagem central da história. Através do título, e também pelo contexto narrativo, podemos inferir que trata-se de uma criança. O texto faz menção a um "muro alto", certamente aos olhos de um indivíduo de estatura pequena, como uma criança e, mais especialmente, pelo desejo de obter a bola de futebol. Quando temos que "a gurizada incentiva", notamos também a expressão "gurizada" característica do vocabulário sul-rio-grandense, de onde a obra é escrita e que faz menção justamente à "criançada".

Tendo em vista que a personagem central deste miniconto trata-se de uma criança, embora não se refira a uma obra voltada ao público infantil, observamos que uma voz, minoritária, ganha destaque. Conforme o estudioso Anderson da Mata (2015), na literatura infantojunvenil as crianças são postas em evidência, contudo, nas produções não segmentadas a esse público a infância é transformada em uma temática de ordem periférica. Nas palavras do autor:

Assim, em um primeiro momento, ao se tratar da representação da infância na literatura, tem-se em mente a tematização da infância a 
partir de personagens infantis e de suas experiências. Há aqui o entendimento da representação como mera recriação verossimilhante das crianças, de seus gestos, dos espaços em que elas circulam e da configuração social na qual estão inseridas. [...]Nesse sentido, a infância pode ser um simples tópico explorado pelo autor, em textos nos quais a criança é narrada por um olhar externo e a infância se transforma em um tema visto de fora, seja pelo viés da nostalgia, da denúncia ou do estranhamento, sem que haja uma tentativa de se recriar um mundo afetado pelo olhar infantil (MATA, 2015, p. 01).

Ao observarmos o texto "Muralhas da Infância" concluímos que a infância não está representada simplesmente no sentido de reproduzir ações infantis, mas, para além disso, nos provoca a possibilidade de leituras sobre o que acontece neste universo.

Há, por exemplo, algumas personagens, também infantis, buscando incentivar a criança protagonista a alcançar o que há do outro lado. Temos um muro como impeditivo, não somente para alcançar a bola, que pode pertencer às personagens e ter caído do outro lado, como pode pertencer a quem mora do outro lado, o general. Observamos, ainda, outros elementos que chamam a atenção da personagem infantil: "pitanga, laranja madura e goiaba". Notamos, a partir disso que há alguma circunstância impedindo a personagem infantil de ter acesso às frutas mencionadas, o que nos permite compreender que, talvez, tratem-se de crianças com condições financeiras limitadas. Ademais, a referência sobre a brincadeira na rua, e no momento em que "acelera o cinamomo", também inferimos que o brinquedo é um carro, mas feito de uma planta, conotando o improviso, a brincadeira que se realiza mais com a imaginação do que com outros artefatos

A criança, muito provavelmente pertencente a uma classe social economicamente menos favorecida daquela do dono do outro lado do muro, deparase com o cachorro do general que habitualmente é associado a um status relacionado a poder, o que é enfatizado na narrativa já que, não somente o muro impõe-se como limite, como o cachorro que pertence ao dono da propriedade e protege aquele espaço, ao qual a criança não pode alcançar.

Já o curta-metragem "Um animal menor" tem duração de 20 minutos e 35 segundos e apresenta duas personagens: uma mulher, presa a um poço e uma criança, um menino, que a observa. Diferente da narrativa textual, a fílmica permite que, ao invés de inferirmos quem são e como são fisicamente as personagens, 
possamos visualizá-las do modo como foram pensadas para aquele enredo. Entretanto, neste filme, nem todos os detalhes são revelados pois, nem pela aparência, e tampouco pelos diálogos, podemos supor outras condições das personagens - como a pobreza, por exemplo -, apenas sabemos que trata-se, de uma mulher e de uma criança.

O impeditivo da mulher, que não tem nome, é o poço, feito de tijolos, que remetem a um muro, como na narrativa literária que destacamos. Não nos é mostrado como e porque ela caiu no poço. Ela veste apenas um vestido, tem dificuldade de levantar-se e tenta, em vão, subir para libertar-se. Pela abertura do poço vê o céu e alguns pássaros, enquanto grita por socorro. As imagens, dentro do poço, são bastante escuras e a trilha sonora é de suspense todo o tempo. Após alguns gritos aparece um menino que, com poucas palavras, promete ajudá-la. $O$ garoto, que diz chamar-se José, vai e volta mas sem perspectiva de tirá-la do poço, oferece alguns alimentos e remédio mas não parece importar-se muito em auxiliar a outra personagem a desvencilhar-se da situação. Há momentos de tensão entre os dois, desde declarações de carinho, passando por ironias e, principalmente, diálogos agressivos. A impressão que temos é que o menino pode ser fruto da imaginação da personagem feminina. Em uma das discussões, José promete entregar remédios e curativos à mulher caso ela prove seu amor por ele tirando sua roupa. A personagem diz que atenderá ao pedido mas não o faz.

Ao final do filme, temos a imagem da mulher, ainda no poço, e do menino correndo com uma grande corta, possivelmente para resgatá-la, embora não possamos afirmar esta ação, já que a narrativa chega ao fim antes de percebermos o que José fará com a corda.

Temos, nesta história, as duas personagens centrais do grupo minoritário, tanto a criança, como a mulher. No entanto, neste filme, a criança detém o poder e parece ter o pensamento de um adulto, enquanto a mulher é mostrada como frágil, machucada e impedida pelo poço. Esta afirmativa pode ir ao encontro do título da produção "um animal menor" que pode referir-se à criança, um homem que na visão (ou até no imaginário) da personagem feminina, pretende a iludir ou aproveitar-se dela, e, por ser uma criança, o termo "menor", ou, por outro lado, o título pode dizer respeito a mulher do poço, vista, aos olhos do menino, como inferior, já que ele detém o comando. 
Sendo assim, observamos que o filme apresenta um impasse à personagem que não consegue sair de um poço, ao passo em que na narrativa literária, um muro está diante da personagem central, uma criança. Deste modo, a partir da análise comparativa, percebemos que as personagens centrais, que tratam-se de minorias sociais, metaforicamente, estão impossibilitadas de exercerem o direito de ir e vir, uma vez que há um limite impeditivo.

Afirmamos a metáfora, quando, ao remetermos às questões sociais e pensando no lugar dos grupos minoritários, esse limite impeditivo, o muro, pode ir para além da narrativa posta e, ao interpretarmos o papel reflexivo destas produções, tratarmos ainda sobre outras diversas questões. Isso quer dizer, os "muros" que impedem uma criança, especialmente uma criança pobre, a ter direitos como educação, lazer, alimentação, saúde, entre outros fatores. Ou os "poços", que bloqueiam as mulheres a conquistar alguns de seus direitos, como o fim do machismo, representado neste curta através da ilusão.

Cinema e Literatura, embora tenham modos de narrar diferenciados, são áreas que se aproximam e podem assumir um caráter de combatividade ou conformismo diante de situações que envolvem as minorias.Percebemos que o miniconto, com poucas palavras consegue proporcionar esta reflexão, tratando da dualidade muro e mundo.Já o curta-metragem, um pouco mais amplo, 20 minutos, mas ainda assim configurado como narrativa curta, apresenta a personagem mulher como principal, mostrando suas angústias, e o modo como ela está impedida de fazer o que gostaria.

A partir do contexto vivenciado pelas protagonistas, poderemos discorrer sobre espaços e desafios presentes na sociedade. Ao representá-las dessa forma, as narrativas retratam realidades, mas de forma metafórica. Retornando ao início deste estudo, podemos perceber, então, que os produtos artísticos que analisamos utilizam elementos que, para além de buscar imitar realidades, propiciam novas formas de compreendê-las, contribuindo para as reflexões acerca das minorias sociais.

Ao comparar estes discursos, observamos que independente do meio pelo qual a temática é abordada, há um sentido dual na representação das personagens que não almejam unicamente desvencilhar-se dos limites que lhes são impostos 
mas, sobretudo, ultrapassar barreiras sociais, comuns a diversas minorias, sejam elas de classe, gênero, raça ou outra.

\section{REFERÊNCIAS}

AUERBACH, Erich. Mimesis. Trad. George Bernard Sperber. São Paulo: Perspectiva, 1971.

CALEGARI, Lizandro Carlos. O cânone literário e as expressões de minorias: implicações e significações históricas. REVELL Revista de Estudos Literários da UEMS ANO 3, v.2, Número 5. 2012. Disponível em: <http://periodicosonline.uems.br/index.php/REV/article/viewFile/354/324>. Acesso em 02 dez 2016.

CANDIDO, Antonio. Vários Escritos. 0 Direito à literatura. 3 ed. rev. e ampl. São Paulo: Duas Cidades, 1995.

CANDIDO, Antonio. Literatura e Sociedade. São Paulo: T.A. Queiroz, 2000, p. 1735 .

DALCASTAGNÈ, Regina. Vozes nas sombras: representação e legitimidade na narrativa contemporânea. In: (Org.). Ver e imaginar o outro: alteridade, desigualdade, violência na literatura brasileira contemporânea. São Paulo: Editora Horizonte, 2008. p. 78-107.

DALCASTAGNÈ, Regina. A personagem do romance brasileiro contemporâneo: 1990-2004. Estudos de Literatura Brasileira Contemporânea.n.ำ 26. Brasília, jul/dez 2005, p. 13-71. Disponível em: <http://periodicos.unb.br/index.php/estudos/article/view/2123>. Acesso em: 15 jun 2016.

HARRES, Pedro; CONTRERAS, Marcos. Um animal menor. Okna Produções Culturais Ltda. 2010.

LIMA, Luiz Costa. Mímesis e modernidade: formas das sombras. 2. ed. São Paulo: Paz e Terra, 2003.

LIMA, Luiz Costa. História, literatura, ficção. São Paulo: Companhia das Letras, 2006.

MATA, Anderson Luis Nunes da. Infância na literatura brasileira contemporânea: tema, conceito, poética. Estudos de Literatura Brasileira Contemporânea n.46 Brasília July/Dec. $2015 . \quad$ Disponível em: <http://www.scielo.br/scielo.php?script=sci_arttext\&pid=S231640182015000200013>. Acesso em 31 mar 2017. 
MELLO, Ana. Minicontando. Porto Alegre: Casa Verde, 2009.

OLIVEIRA, Rejane Pivetta de. Lukács: Mimese e implicações de leitura. In: BORDINI, Maria da Glória; SENSEVERINO, Antônio Marcos et al (Orgs.). Lukács e a literatura. Porto Alegre: Edipucrs, 2003. p. 181-208. 